\title{
PENJADWALAN KULIAH DENGAN ALGORITMA WELSH-POWELL (STUDI KASUS: JURUSAN MATEMATIKA FMIPA UNAND)
}

\author{
PUTRI WULAN SARI, LYRA YULIANTI, NARWEN \\ Program Studi Matematika, \\ Fakultas Matematika dan Ilmu Pengetahuan Alam, Universitas Andalas, \\ Kampus UNAND Limau Manis Padang, Indonesia, \\ email: sputriwulan13@yahoo.co.id
}

\begin{abstract}
Abstrak. Penjadwalan kuliah merupakan suatu pekerjaan rutin dalam sistem akademik perguruan tinggi yang dilakukan setiap semester. Permasalahan yang kerap muncul adalah terjadinya bentrok waktu perkuliahan baik dari segi dosen yang mengajar maupun mahasiswa yang mengikuti perkuliahan. Berdasarkan permasalahan tersebut, pada tulisan ini akan disusun jadwal kuliah jurusan Matematika FMIPA UNAND melalui pewarnaan titik graf menggunakan algoritma Welsh-Powell. Dengan algoritma ini, dapat disusun kelompok-kelompok mata kuliah yang tidak dapat dilaksanakan waktunya secara bersamaan, dan yang dapat dilaksanakan dalam waktu yang bersamaan. Kelompok mata kuliah yang dapat bersamaan waktunya ini disusun dalam jadwal perkuliahan yang terdapat jurusan Matematika FMIPA UNAND.

Kata Kunci: Penjadwalan, Pewarnaan titik, Algoritma Welsh-Powell, Matriks ketetanggaan
\end{abstract}

\section{PENDAHULUAN}

Teori graf merupakan cabang ilmu matematika yang memiliki peranan penting dalam pengembangan ilmu matematika. Hal ini terbukti dengan banyaknya penyelesaian masalah dengan menggunakan graf. Graf memiliki aplikasi yang sangat luas. Salah satunya pewarnaan graf (graph coloring). Banyak dari kehidupan sehari-hari yang memiliki karakteristik seperti mewarnai graf. Salah satu aplikasi dalam pewarnaan graf adalah persoalan dalam menyusun jadwal kuliah di suatu perguruan tinggi.

Penjadwalan kuliah merupakan suatu pekerjaan rutin dalam sistem akademik perguruan tinggi yang dilakukan setiap semester. Pada pelaksanaannya sering jadwal perkuliahan yang telah dikeluarkan belum fix sehingga membutuhkan adanya penjadwalan ulang. Hal ini disebabkan jenis mata kuliah yang banyak dan variasi pengambilan mata kuliah dari mahasiswa yang banyak juga. Pada dasarnya dalam menentukan jadwal kuliah harus diatur sedemikian rupa sehingga semua mahasiswa dapat mengikuti perkuliahan yang diambilnya tanpa bertabrakan waktunya [4].

Apabila dilakukan secara manual, maka proses penjadwalan mata kuliah akan memerlukan waktu yang cukup lama, dan selalu terdaoat kemungkinan adanya 
pelanggaran constraint akibat human error. Masalah ini dapat diselesaikan dengan salah satu konsep dalam teori graf, yaitu dengan pewarnaan graf. Penjadwalan kuliah yang menerapkan konsep pewarnaan dalam graf ini diharapkan mampu menjawab permasalahan tersebut [4].

Pada makalah ini akan dibahas tentang penyusunan jadwal mata kuliah semester ganjil tahun ajaran 2017/2018 di Jurusan Matematika FMIPA Universitas Andalas dengan pewarnaan titik pada graf, menggunakan algoritma Welsh-Powell.

Batasan yang menjadi acuan dalam masalah ini adalah sebagai berikut.

(1) Penjadwalan kuliah yang disusun adalah untuk semester ganjil Tahun Ajaran $2017 / 2018$.

(2) Setiap angkatan diasumsikan memiliki dua kelas yaitu A dan B.

(3) Ruangan kuliah untuk Jurusan Matematika FMIPA UNAND dianggap selalu tersedia.

(4) Jika terdapat mahasiswa yang mengulang suatu mata kuliah, maka mahasiswa tersebut hanya diperbolehkan mengulang mata kuliah satu tingkat di bawahnya; jika ada mahasiswa yang ingin mengambil mata kuliah ke atas dengan syarat IPK yang ditentukan hanya diperbolehkan mengambil mata kuliah satu tingkat di atasnya.

(5) Untuk mata kuliah pilihan pada semester 3 dan 5 dibuat menjadi dua kelas. Sedangkan mata kuliah pilihan pada semester 7 hanya terdiri dari satu kelas.

(6) Jadwal tutorial tidak dipertimbangkan.

\section{LANDASAN TEORI}

\subsection{Definisi dan Terminologi Graf}

Suatu graf $G=(V, E)$ adalah pasangan himpunan terurut $V(G)$ dan $E(G)$, dimana $V(G)$ adalah himpunan titik dan $E(G)$ adalah himpunan sisi. Misal $V=$ $\left\{v_{1}, v_{2}, \cdots, v_{n}\right\}$ adalah himpunan dengan $n$ titik dan $E=\left\{e_{1}, e_{2}, \cdots, e_{m}\right\}$ adalah himpunan dengan $m$ sisi. Secara umum, untuk menotasikan sisi dapat ditulis dengan $v_{i} v_{j}$ atau $v_{j} v_{i}$. Sepasang titik $v_{i} v_{j}$ dari $V$ adalah bertetangga jika $v_{i} v_{j} \in E(G)$. Derajat (degree) dari $v$ adalah banyaknya titik yang bertetangga ke $v$, dinotasikan dengan $\operatorname{deg}(v)$.

Dalam tulisan ini, graf yang digunakan adalah graf sederhana, yaitu graf yang tidak memuat loop dan sisi ganda. Suatu graf $G$ dikatakan graf terhubung (connected graph) jika untuk setiap pasang titik $u, v \in V(G)$ terdapat suatu lintasan yang menghubungkan $u$ dan $v$. jika sebaliknya maka graf tersebut dikatakan graf tidak terhubung (disconnected graph).

Definisi 2.1. [2] Misalkan terdapat graf $G$ dengan banyak titik n. Matriks Ketetanggaan dari graf $G$, dinotasikan dengan $A(G)=\left[a_{i j}\right]$, adalah matriks berukuran $n \times n$ dengan:

$$
a_{i, j}=\left\{\begin{array}{l}
1, \quad \text { jika titik } v_{i} \text { dan titik } v_{j} \text { bertetangga } \\
0, \quad \text { jika titik } v_{i} \text { dan titik } v_{j} \text { tidak bertetangga }
\end{array}\right.
$$




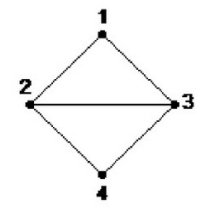

$\begin{array}{lllll}1 & 2 & 3 & 4\end{array}$

$1\left[\begin{array}{llll}0 & 1 & 1 & 0\end{array}\right]$

$2 \mid \begin{array}{lllll}1 & 0 & 1 & 1\end{array}$

$3 \quad 111001$

$4\left[\begin{array}{llll}0 & 1 & 1 & 0\end{array}\right]$

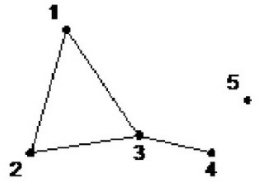

$\begin{array}{llllll}1 & 2 & 3 & 4 & 5\end{array}$

$1\left[\begin{array}{lllll}0 & 1 & 1 & 0 & 0\end{array}\right]$

21100100

3111100110

$40 \begin{array}{lllll}0 & 0 & 1 & 0 & 0\end{array}$

$5\left[\begin{array}{lllll}0 & 0 & 0 & 0 & 0\end{array}\right.$

Gambar 1. Contoh Matriks Ketetanggaan suatu Graf

\subsection{Algoritma Welsh-Powell}

Pewarnaan titik (vertex coloring) pada suatu graf $G$ adalah pemberian warna berbeda pada setiap titik yang bertetangga di $G$, sehingga tidak ada dua titik yang bertetangga dengan warna yang sama. Bilangan kromatik graf $G,(\lambda(G))$ adalah banyaknya warna minimum yang dapat digunakan untuk mewarnai titik, sehingga dua titik yang saling bertetangga tidak memiliki warna yang sama [1].

Algoritma Welsh-Powell dapat digunakan untuk mewarnai titik-titik dalam graf secara efisien. Algoritma Welsh-Powell merupaka salah satu algoritma pewarnaan yang melakukan pewarnaan berdasarkan derajat tertinggi dari titik-titiknya. Tujuan dari algoritma ini adalah untuk memperoleh warna minimum yang dapat diberikan pada suatu graf sedemikian sehingga setiap titik yang bertetangga pada graf tersebut tidak memiliki warna yang sama.

Algoritma Welsh-Powell dinyatakan sebagai berikut [3]:

(1) Urutkan titik-titik dalam graf $G$ dalam derajat dimulai dari derajat terbesar ke derajat terkecil.

(2) Gunakan warna pertama untuk mewarnai titik pertama (yang mempunyai derajat paling tinggi) dan titik lain (sesuai dengan urutannya)selama titik-titik tersebut tidak saling bertetangga. Jika salah satu dari titik-titik tesebut bertetangga maka masuk kelangkah selanjutnya.

(3) Mulailah lagi dengan titik yang memiliki derajat tertinggi berikutnya dalam daftar terurut yang masih belum diwarnai. Ulangi proses ini dengan menggunakan warna kedua.

(4) Ulangi pemberian warna-warna sampai semua titik telah diwarnai.

\section{ALGORITMA WELSH-POWELL UNTUK PENYUSUNAN JADWAL KULIAH}

\subsection{Matriks Ketetanggaan}

Misalkan graf $G=(V, E)$ adalah graf dengan himpunan titik adalah himpunan semua mata kuliah yang ada di semester ganjil tahun 2017/2018 di Jurusan Matematika FMIPA UNAND, sementara himpunan sisi adalah semua dosen yang mengajar pada mata kuliah semester ganjil tahun 2017/2018 Jurusan Matematika FMIPA 
Universitas Andalas atau semua mahasiswa Jurusan Matematika FMIPA Universitas Andalas yang mengikuti perkuliahan di semester ganjil tahun 2017/2018. Akan dibentuk suatu matriks ketetanggaan dari $G$, notasikan dengan $A(G)=\left[a_{i j}\right]$ dimana

$$
a_{i, j}= \begin{cases}1, & \text { jika titik } v_{i} \text { dan titik } v_{j} \text { bertetangga, } \\ 0, & \text { jika titik } v_{i} \text { dan titik } v_{j} \text { tidak bertetangga, }\end{cases}
$$

Titik $v_{i}$ dikatakan bertetangga dengan titik $v_{j}$ jika terdapat dosen yang mengajar pada mata kuliah $i$ yang juga mengajar pada mata kuliah $j$, atau mahasiswa yang mengambil mata kuliah $i$ juga mengambil mata kuliah $j$. Artinya mata kuliah $i$ dan $j$ tidak dapat dilaksanakan dalam waktu yang sama, karena akan mengakibatkan bentrok baik dari dosen yang mengajar maupun mahasiswa yang mengambil mata kuliah tersebut.

Sebaliknya titik $v_{i}$ dikatakan tidak bertetangga dengan titik $v_{j}$ jika dosen yang mengajar pada mata kuliah $i$ tidak mengajar pada mata kuliah $j$ dan mahasiswa yang mengambil mata kuliah $i$ tidak mengambil mata kuliah $j$. Artinya mata kuliah $i$ dan $j$ dapat dilaksanakan dalam waktu yang sama, karena tidak akan mengakibatkan bentrok baik dari dosen yang mengajar maupun mahasiswa yang mengambi mata kuliah tersebut.

Mata kuliah semester ganjil tahun ajaran 2017/2018 terdiri dari 15 mata kuliah wajib, yang masing-masingnya terdiri dari dua kelas, dan 15 mata kuliah pilihan, dengan rincian:

(1) Tujuh mata kuliah pilihan untuk tahun 2 dan 3, yang dibagi menjadi dua kelas,

(2) Delapan mata kuliah pilihan untuk tahun 4, dengan masing-masingnya terdiri dari satu kelas.

Diperoleh total mata kuliah ada 52, sehingga graf $G$ terdiri dari 52 titik. Maka matriks ketetanggaan yang akan dibuat berukuran $52 \times 52$. Adapun hal-hal yang perlu dipertimbangkan dan menjadi batasan dalam penyusunan matriks ketetanggaan dari masalah ini adalah:

(1) Jika terdapat mahasiswa yang mengulang suatu mata kuliah baik wajib maupun pilihan, maka mahasiswa tersebut hanya diperbolehkan mengulang mata kuliah tersebut satu tingkat di bawahnya. Sebaliknya jika ada mahasiswa yang ingin mengambil mata kuliah ke atas dengan syarat IPK yang ditentukan, maka mahasiswa tersebut hanya diperbolehkan mengambil mata kuliah satu tingkat di atasnya.

(2) Dalam pengambilan mata kuliah pilihan, mahasiswa dianjurkan mengambil mata kuliah pilihan sesuai dengan tingkatan semesternya dan sesuai dengan kelas dimana mahasiswa tersebut mengambil mata kuliah wajib. Contohnya mahasiswa X terdaftar di kelas A maka ia diwajibkan mengambil mata kuliah wajib maupun mata kuliah pilihan pada kelas A. Sehingga untuk semua mata kuliah pilihan dengan kelas yang sama saling bertetangga. Kecuali mata kuliah pilihan dengan kode awalan 4 hanya diperbolehkan untuk mahasiswa tahun 4 dan hanya terdapat 1 kelas. 
Pada Tabel 1 diberikan daftar nama mata kuliah beserta dosen yang mengajar.

Tabel 1. Daftar Nama Mata Kuliah Beserta Dosen yang Mengajar

\begin{tabular}{|c|c|c|c|}
\hline \multicolumn{4}{|c|}{ DAFTAR MATA KULIAH SEMESTER 1} \\
\hline NO & MATA KULIAH & DOSEN & KODE \\
\hline 1 & Kalkulus $1 \mathrm{~A}$ & Syafruddin & PAM $121 \mathrm{~A}$ \\
\hline 2 & Kalkulus $1 \mathrm{~B}$ & Bukti Ginting & PAM $121 \mathrm{~B}$ \\
\hline 3 & Pengantar Matematika A & Susila Bahri & PAM $123 \mathrm{~A}$ \\
\hline 4 & Pengantar Matematika B & Haripamyu & PAM $123 \mathrm{~B}$ \\
\hline 5 & Bahasa Inggris Matematika A & Dodi Devianto / Ferra Yanuar & PAM $111 \mathrm{~A}$ \\
\hline 6 & Bahasa Inggris Matematika B & Dodi Devianto / Ferra Yanuar & PAM $111 \mathrm{~B}$ \\
\hline 7 & Fisika Dasar A & Afdal & PAP $111 \mathrm{~A}$ \\
\hline 8 & Fisika Dasar B & Ardian Putra & PAP $111 \mathrm{~B}$ \\
\hline 9 & Kimia Dasar A & Admi & PAK $111 \mathrm{~A}$ \\
\hline 10 & Kimia Dasar B & Refilda & PAK $111 \mathrm{~B}$ \\
\hline 11 & Agama A & Rusydja Rustam & HKU $141 \mathrm{~A}$ \\
\hline 12 & Agama B & Rusydja Rustam & HKU $141 \mathrm{~B}$ \\
\hline 13 & Bahasa Indonesia $\mathrm{A}$ & Sonezza Ladyana & SSI $121 \mathrm{~A}$ \\
\hline 14 & Bahasa Indonesia B & Noviatri & SSI $121 \mathrm{~B}$ \\
\hline \multicolumn{4}{|c|}{ DAFTAR MATA KULIAH SEMESTER 3} \\
\hline $\mathrm{NO}$ & MATA KULIAH & DOSEN & KODE \\
\hline 1 & Aljabar Linier Elementer A & Yanita & PAM $231 \mathrm{~A}$ \\
\hline 2 & Aljabar Linier Elementer B & Nova Noliza Bakar & PAM $231 \mathrm{~B}$ \\
\hline 3 & Pemprograman Komputer $2 \mathrm{~A}$ & Narwen & PAM $251 \mathrm{~A}$ \\
\hline 4 & Pemprograman Komputer $2 \mathrm{~B}$ & Narwen & PAM $251 \mathrm{~B}$ \\
\hline 5 & Persamaan Differensial Biasa A & Ahmad Iqbal Baqi / Jenizon & PAM 253 A \\
\hline 6 & Persamaan Differensial Biasa B & Efendi / Riri Lestari & PAM $253 \mathrm{~B}$ \\
\hline 7 & Kalkulus Peubah Banyak A & Zulakmal & PAM $241 \mathrm{~A}$ \\
\hline 8 & Kalkulus Peubah Banyak B & Effendi & PAM $241 \mathrm{~B}$ \\
\hline \multicolumn{4}{|c|}{ DAFTAR MATA KULIAH SEMESTER 5} \\
\hline $\mathrm{NO}$ & MATA KULIAH & DOSEN & KODE \\
\hline 1 & Aljabar $1 \mathrm{~A}$ & Nova Noliza Bakar & PAM $331 \mathrm{~A}$ \\
\hline 2 & Aljabar $1 \mathrm{~B}$ & I Made Arnawa & PAM $331 \mathrm{~B}$ \\
\hline 3 & Analisis Riil 1 A & Muhafzan / Syafrizal Sy & PAM $341 \mathrm{~A}$ \\
\hline 4 & Analisis Riil $1 \mathrm{~B}$ & Haripamyu / Jenizon & PAM 341 B \\
\hline 5 & Statistika Matematika $2 \mathrm{~A}$ & $\begin{array}{l}\text { Hazmira Yozza / Izzati Rahmi } \\
\text { Yudiantri Asdi }\end{array}$ & PAM $361 \mathrm{~A}$ \\
\hline 6 & Statistika Matematika $2 \mathrm{~B}$ & $\begin{array}{l}\text { Hazmira Yozza / Izzati Rahmi } \\
\text { Yudiantri Asdi }\end{array}$ & PAM $361 \mathrm{~B}$ \\
\hline \multicolumn{4}{|c|}{ DAFTAR MATA KULIAH SEMESTER 7} \\
\hline $\mathrm{NO}$ & MATA KULIAH & DOSEN & KODE \\
\hline 1 & Pemodelan Matematika A & $\begin{array}{l}\text { Ferra Yanuar / Mahdhivan S./ } \\
\text { Susila Bahri }\end{array}$ & PAM $451 \mathrm{~A}$ \\
\hline 2 & Pemodelan Matematika B & $\begin{array}{l}\text { Ferra Yanuar / Mahdhivan S./ } \\
\text { Susila Bahri }\end{array}$ & PAM $451 \mathrm{~B}$ \\
\hline
\end{tabular}




\begin{tabular}{|l|l|l|l|}
\hline \multicolumn{4}{|c|}{ DAFTAR MATA KULIAH PILIHAN } \\
\hline NO & MATA KULIAH & DOSEN & KODE \\
\hline 1 & Algoritma Dan Struktur Data & Narwen & PAM 335 \\
\hline 2 & Analisis Peubah Ganda & Maiyastri / Rahmat Syafni & PAM 461 \\
\hline 3 & Analisis Regresi & Dodi Devianto/ Hazmira Yozza & PAM 363 \\
\hline 4 & Kapita Selekta Aljabar 1 & Yanita & PAM 431 \\
\hline 5 & Kapita Selekta Analisis 1 & Admi Nazra & PAM 441 \\
\hline 6 & $\begin{array}{l}\text { Kapita Selekta Matematika } \\
\text { Kombinatorika 1 }\end{array}$ & Lyra Yulianti & PAM 471 \\
\hline 7 & Kapita Selekta Matematika \\
& Terapan 2 & Mahdhivan Syafwan & PAM 454 \\
\hline 8 & Kapita Selekta Statistika 2 & Dodi Devianto / Maiyastri & PAM 463 \\
\hline 9 & Optimasi & Efendi & PAM 455 \\
\hline 10 & Matematika Populasi & Ahmad Iqbal Baqi / Efendi & PAM 351 \\
\hline 11 & Pengantar Matematika & Keuangan Riri Lestari & PAM 353 \\
\hline 12 & Pengantar Teori Graf & Syafrizal / Lyra Yulianti & PAM 271 \\
\hline 13 & Sejarah Matematika & Budi Rudianto & PAM 211 \\
\hline 14 & Sistem Kontrol Linier & Muhafzan & PAM 457 \\
\hline 15 & Teknik Sampling & Hazmira Yozza / Izzati Rahmi HG & PAM 365 \\
\hline
\end{tabular}

\subsection{Penerapan Algoritma Welsh-Powell}

Langkah-langkah dalam penyusunan jadwal kuliah Semester ganjil 2017/2018 Jurusan Matematika FMIPA UNAND dapat dituliskan sebagai berikut.

(1) Mengumpulkan data nama mata kuliah apa saja yang terdapat pada semester ganjil 2017/2018 Jurusan Matematika FMIPA UNAND beserta dengan dosen yang mengajar mata kuliah tersebut. Susun daftar nama mata kuliah beserta dosennya tersebut berdasarkan tingkatan semester dan kelasnya.

(2) Buat matriks ketetanggaan dari masing-masing mata kuliah tersebut berdasarkan dosen yang mengajar atau mahasiswa yang mengambil mata kuliah tersebut dalam tingkat yang sama. Untuk himpunan titiknya adalah semua mata kuliah yang terdapat di semester ganjil 2017/2018 Jurusan Matematika FMIPA UNAND. Untuk himpunan sisinya adalah nama dosen yang mengajar pada mata mata kuliah tersebut atau mahasiswa yang akan mengambil mata kuliah tersebut. Gunakan persamaan (3.1) dalam menentukan apakah 2 mata kuliah bertetangga atau tidak.

(3) Hitung derajat dari masing-masing titik yang telah disusun matriks ketetanggaannya, berdasarkan jumlah entri-entri pada masing-masing baris atau masing-masing kolom.

(4) Terapkan Algoritma Welsh-Powell.

(5) Setelah penerapan algoritma Welsh-Powell dilakukan, maka didapatkan banyaknya jadwal kelompok mata kuliah berdasarkan bilangan kromatiknya. Sehingga dalam 1 kelompok jadwal mata kuliah dapat dilaksanakan waktunya secara bersamaan karena tidak akan mengakibatkan bentrok baik dari dosen pengajarnya atau mahasiswa yang mengikuti perkuliahan tersebut.

Diperoleh mata kuliah yang dapat bersamaan waktunya adalah sebagai berikut. 
140 Putri Wulan Sari dkk.

(1) PAM 463, PAM 253 B, PAM 271 A

(2) PAM 363 A, PAM 341 B, PAM 123 A, PAM 121 B.

(3) PAM 363 B, PAM 335 A, PAM 123 B, PAM 121 A.

(4) PAM 471, PAM 251 A, PAM 241 B.

(5) PAM 431, PAM 271 B, PAM 253 A.

(6) PAM 455, PAM 251 B, PAM 231 A.

(7) PAM 361 A, PAM 335 B, PAM 111 A, PAP 111 B.

(8) PAM 361 B, PAM 351 A, PAM 111 B, PAP 111 A.

(9) PAM 461, PAM 211 A, PAM 231 B.

(10) PAM 441, PAM 211 B, PAM 241 A.

(11) PAM 454, PAK 111 A, PAK 111 B.

(12) PAM 457, HKU 141 A, SSI 121 B.

(13) PAM 365 A, PAM 351 B, SSI 121 A, HKU 141 B.

(14) PAM 365 B, PAM 353 A.

(15) PAM 353 B, PAM 341 A.

(16) PAM 331 A, PAM 451 B.

(17) PAM 331 B, PAM 451 A.

Hasil di atas merupakan banyaknya kelompok jadwal mata kuliah berdasarkan bilangan kromatiknya, dimana diperoleh bilangan kromatik sebanyak $\lambda(G)=17$. Artinya kelompok-kelompok jadwal mata kuliah di atas adalah daftar nama mata kuliah yang dapat dilaksanakan waktunya secara bersamaan tanpa terjadi bentrok baik dari dosen yang mengajar maupun mahasiswa yang mengikuti perkuliahan tersebut.

Berdasarkan hasil di atas, dapat disusun pula jadwal kuliah dari hari Senin hingga Jumat dengan jadwal pukul 07:30- 17:40. Pada Tabel 2 diberikan contoh jadwal yang dapat dibentuk berdasarkan kelompok-kelompok mata kuliah diatas.

\section{KESIMPULAN}

Penerapan algoritma Welsh-Powell pada kasus penyusunan jadwal kuliah semester ganjil tahun Ajaran 2017 / 2018 di Jurusan Matematika FMIPA UNAND dapat dikatakan efektif, karena memiliki variasi mata kuliah yang berbeda baik mata kuliah wajib ataupun pilihan, mahasiswa dari tingkat 1 sampai tingkat 4 dan tidak ada dosen yang mengajar di dua kelas dalam waktu yang bersamaan. Hari yang digunakan untuk waktu perkuliahan mengikuti dengan hari efektif kuliah yaitu dari hari Senin hingga Jum'at sedangkan untuk waktunya dari pukul 07:30-17:40 yang mana waktu setiap pertemuan disesuaikan dengan bobot SKS mata kuliah yang bersangkutan. Dari permasalahan titik ini diperoleh warna seminimum mungkin, sehingga bilangan kromatik adalah 17 yang menunjukkan terdapat 17 kelompok mata kuliah yang efektif. Contoh jadwal kuliah yang telah dibuat tersebut dapat modifikasi kembali apabila kebutuhannya berubah.

\section{Daftar Pustaka}

[1] Bondy. J. A. dan U. S. R Murty. 1976. Graph Theory with Application. London 
Tabel 2. Contoh Jadwal Kuliah Semester Ganjil Tahun Ajaran 2017/2018

\begin{tabular}{|c|c|c|c|c|c|}
\hline Waktu & Senin & Selasa & Rabu & Kamis & Jum'at \\
\hline \multirow[t]{2}{*}{ 07:30-09:10 } & PAM $123 \mathrm{~B}$ & PAM $123 \mathrm{~A}$ & PAM $123 \mathrm{~B}$ & PAM $241 \mathrm{~B}$ & PAM $341 \mathrm{~A}$ \\
\hline & PAM $121 \mathrm{~A}$ & PAM $121 \mathrm{~B}$ & PAM $121 \mathrm{~A}$ & PAM $241 \mathrm{~A}$ & PAM 361 B \\
\hline \multirow[t]{2}{*}{$07: 30-10: 00$} & PAM 363 B & PAM $365 \mathrm{~A}$ & PAM 365 B & PAM 463 & PAM $111 \mathrm{~A}$ \\
\hline & PAM 335 A & PAM 335 B & PAM $353 \mathrm{~A}$ & PAM 455 & PAK $111 \mathrm{~B}$ \\
\hline \multirow{2}{*}{ 09:20 - 11: 00} & HKU $141 \mathrm{~A}$ & SSI 121 A & PAM $123 \mathrm{~A}$ & PAM 231B & PAM $361 \mathrm{~A}$ \\
\hline & SSI $121 \mathrm{~B}$ & HKU $141 \mathrm{~B}$ & PAM $121 \mathrm{~B}$ & PAM $231 \mathrm{~A}$ & PAM 341 B \\
\hline & & & & & \\
\hline \multirow{3}{*}{$11: 10-12: 50$} & PAM $231 \mathrm{~A}$ & PAM 253 B & PAM $241 \mathrm{~A}$ & PAM $253 \mathrm{~B}$ & \\
\hline & PAM $231 \mathrm{~B}$ & PAM $253 \mathrm{~A}$ & PAM $241 \mathrm{~B}$ & PAM $253 \mathrm{~A}$ & \\
\hline & PAM $451 \mathrm{~B}$ & PAM $451 \mathrm{~A}$ & PAM $451 \mathrm{~B}$ & PAM $451 \mathrm{~A}$ & \\
\hline \multirow{5}{*}{$13: 30-16: 00$} & & & & & \\
\hline & PAM 431 & PAM 454 & PAM $251 \mathrm{~B}$ & PAM $351 \mathrm{~B}$ & PAM $351 \mathrm{~A}$ \\
\hline & PAM $271 \mathrm{~B}$ & PAM 471 & PAM 441 & PAK $111 \mathrm{~A}$ & PAM $111 \mathrm{~B}$ \\
\hline & PAM 461 & PAM $211 \mathrm{~B}$ & PAM $271 \mathrm{~A}$ & PAP $111 \mathrm{~B}$ & PAP $111 \mathrm{~A}$ \\
\hline & PAM $211 \mathrm{~A}$ & PAM $251 \mathrm{~A}$ & PAM 457 & PAM $363 \mathrm{~A}$ & PAM 353 B \\
\hline \multirow[t]{2}{*}{ 16:00 17: 40} & PAM $331 \mathrm{~A}$ & PAM $361 \mathrm{~A}$ & PAM $341 \mathrm{~A}$ & PAM $331 \mathrm{~A}$ & \\
\hline & PAM $331 \mathrm{~B}$ & PAM $341 \mathrm{~B}$ & PAM $361 \mathrm{~B}$ & PAM $331 \mathrm{~B}$ & \\
\hline
\end{tabular}

[2] Rosen. K. 2007. Discrete Mathematics and its Application. Sixth Edition. McGraw-Hill

[3] Welsh, D.J.A, Powell, M. B. 1967. An upper bound for the chromatic number of a graph and its application to timetabling problems. The Computer Journal $10: 85-86$

[4] Astuti, Setia. 2011. Penyusunan Jadwal Ujian Mata Kuliah dengan Algoritma Pewarnaan Graf Welch-Powell. Jurnal Dian 11 (1) 